\title{
Winner of the Classification Society Distinguished Dissertation Award 2009
}

The Award honors the best $\mathrm{PhD}$ (or approximately equivalent doctoral) dissertation nominated by an annual deadline. The theme is clustering, classification, related areas of data analysis, encompassing both associated theory and/or applications.

In 2009 the Award totals US\$500 in book vouchers from Chapman and Hall/CRC. The winner was invited to make a presentation in a special plenary session at the Classification Society's 2009 Annual Meeting with up to $\$ 500$ of the Award winner's travel expenses to the Annual Meeting covered by Classification Society.

In 2008-2009, the evaluation committee included: Samantha C. Bates Prins (Award Committee Chair; Department of Mathematics and Statistics, James Madison University), Fionn Murtagh (Science Foundation Ireland; and Department of Computer Science, Royal Holloway, University of London), Douglas Steinley (Department of Psychological Sciences, University of Missouri-Columbia) and Rebecca Nugent (Departtment of Statistics, Carnegie Mellon University).

The 2009 Distinguished Dissertation Award winner is

\section{Dr. Innar Liiv}

for his dissertation

\section{"Pattern Discovery Using Seriation and Matrix Reordering: A Unified View, Extensions and an Application to Inventory Management" defended at Tallinn University of Technology under supervision of Professor Rein Kuusik, in August 2008.}

Dr. Georgi Nalbantov received an Honorable Mention for his thesis "Essays on Some Recent Penalization Methods with Applications in Finance and Marketing", Erasmus University Rotterdam. All 7 nominations were of excellent quality and are listed at http://www.classificationsociety.org/csna. 